\title{
Catecholamine metabolite excretion in spina bifida
}

\author{
B. McKIBBIN, L. O'GORMAN, AND T. DUCKWORTH \\ From the University Department of Orthopaedics, The Royal Infirmary, Sheffield
}

SYNOPSIS The urinary excretion of vanilmandelic acid (VMA), homovanillic acid (HVA), and parahydroxyphenylacetic acid (pHPAA) was measured in 55 children with meningomyelocoele selected at random. In $96 \%$ of the children the levels of one or other of these compounds was significantly raised above the normal, usually by a factor of about 3. High VMA levels usually meant high HVA levels but the values for pHPAA appeared to be quite independent of the others. These results suggest a disorder of tyrosine metabolism, and the possible implications are discussed.

Previous investigations have shown the rather surprising fact that in over $70 \%$ of children severely paralysed with meningomyelocoele there is a state of vitamin C unsaturation (McKibbin and Porter, 1967). Further studies appear to confirm the deficiency of this vitamin by demonstrating excessive urinary excretion of p-hydroxyphenylacetic acid (pHPAA) in a similar proportion of such children (McKibbin, Toseland, and Duckworth, 1968). pHydroxyphenylpyruvic acid (pHPPA) is an intermediary metabolite in the breakdown of tyrosine (Fig. 1) and requires the presence of vitamin $C$ for its further conversion (Gjessing, 1963). In the absence of vitamin $\mathrm{C}$, therefore, pHPAA appears in the urine in excess (Boscott and Cooke, 1954).

Since there is no evidence to suggest that any of the children in these investigations lacked sufficient vitamin $C$ in the diet, and, as there is no very obvious link between deficiency of this vitamin and a malformation of the central nervous system, we considered the possibility that the results obtained could be the consequence of an intrinsic metabolic defect. The metabolism of tyrosine was chosen for investigation, for not only is vitamin $\mathrm{C}$ concerned in the further degradation of pHPPA but it is also involved in the pathway for the formation of the catecholamines-adrenaline and noradrenalinefrom tyrosine (Levin, Levenberg, and Kaufman, 1960). These compounds do at least provide a link with the central nervous system. We decided therefore to investigate further the tyrosine metabolism of children with spina bifida by measuring the urinary excretion of the major products of the Received for publication 4 March 1969. breakdown of dopamine and noradrenaline, namely, homovanillic acid (HVA) and vanilmandelic acid (VMA).

\section{MATERIAL AND METHOD}

Specimens of urine were obtained from 55 children with meningocoele or meningomyelocoele who were attending a special clinic for this condition. All had had early operations performed to close the defect. No attempt was made to select the children, whose neurological state varied from virtually normal to total paraplegia, but, because in a clinic of this type the more severely affected are seen with greater frequency, there is a disproportionate number of such cases in this series. Many of the children were hydrocephalic and approximately $50 \%$ had been treated with a Spitz-Holter valve.

ASSAY Urinary phenolic acids were extracted from acid hydrolysed urine with diethyl ether $\left(3 \times 1 \frac{1}{2} \mathrm{vol}\right)$ and the extract was subjected to electrophoresis on cellulose thin-layer plates $(20 \times 20 \mathrm{~cm})$ in a buffer of $p \mathrm{H} 3.9$ for two and a half hours at a CP of 600 volts (Hermann, 1964). Chromatographic development at right angles to the electrophoresis in isopropanol-ammonia-water $(8: 1: 1)$ was carried out and quantitation was achieved by spectrophotometry in alkaline methanol after elution and chromogen formation with diazotized p-nitro-aniline, or by visual comparison with standards (Studnitz, 1960).

For comparison 10 of the 55 urine samples were analysed by more sensitive techniques. The VMA was estimated by a ${ }^{14} \mathrm{C}$-radioactive labelling technique (O'Gorman, 1968), and the HVA and pHPAA by gas chromatography (Pye-Argon gas chromatogram; column $10 \%$ Apiezon $\mathrm{L}$ at $180^{\circ} \mathrm{C}$, flash heater $220^{\circ} \mathrm{C}$ ) after trifluoracetylation of their methyl esters.

The creatinine concentration of each urine specimen 


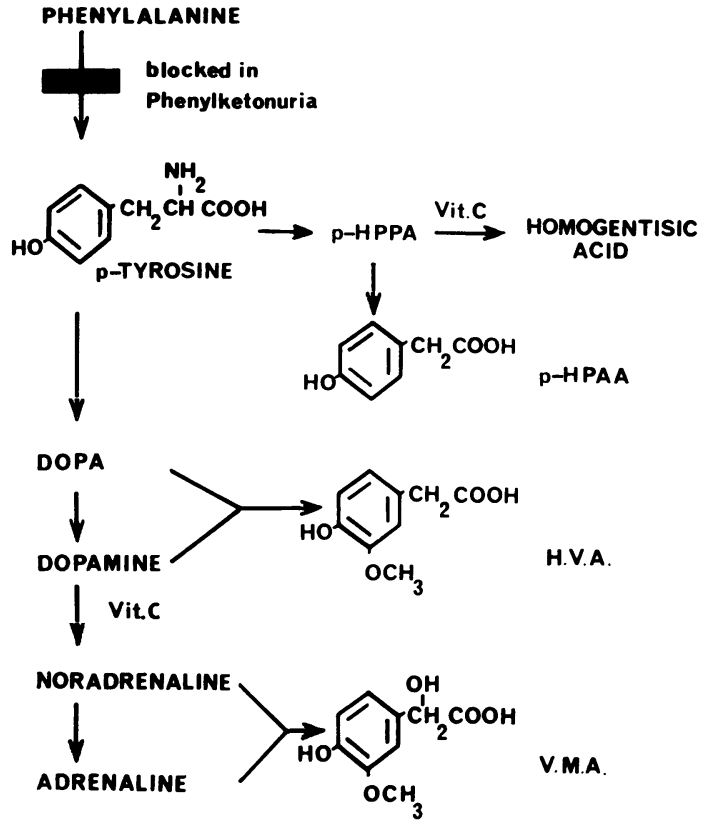

FIG. 1. Pathways of p-tyrosine metabolism (Gjessing, 1963).

was measured by the alkaline picrate method (Bonsnes and Taussky, 1945).

\section{RESULTS}

The data from the investigation are set out in Table I. The 10 VMA values obtained by the isotope method were in agreement with those obtained by the two-way separation technique as were those results obtained by gas chromatographic analysis. The results have been expressed as micrograms per milligram urinary creatinine since 24-hour collections are not a practical possibility on a large scale in these children, many of whom are incontinent. In controls the creatinine ratios showes little variation throughout the day (Table II). Theo patients are divided into three age groups since the normal levels are themselves dependent on age. The $\overline{\frac{p}{7}}$ figures for the control groups have been taken from $\mathbb{\square}$ previously reported investigations (O’Gorman, 1968 n Gitlow, Mendlowitz, Wilk, Wolf, and Glick, 1965)_ also made on random urine samples.

TABLE II

CREATININE RATIOS IN CONTROLS (20 NORMAL CHILDREN

Time of

Collection

Creatinine Ratios

VMA HVA pHPAA

$10 \cdot 0$ a.m.

$\begin{array}{llll}\text { Range } & 2.2 \rightarrow 9.5 & 1.6 \rightarrow 7.2 & 3.6\end{array} \rightarrow 18.9$

Mean

2.0 p.m.

Range

Mean

6.0 p.m.

Range

Mean

$5 \cdot$

$5 \cdot 2$

$3 \cdot 3$

$9 \cdot 6$

$3 \cdot 4 \rightarrow 7 \cdot 1$

$5 \cdot 1$

$2 \cdot 7 \rightarrow 7 \cdot 6$

$5 \cdot 5$

$1 \cdot 0 \rightarrow 8 \cdot 4$

$4 \cdot 3$

$1 \cdot 0 \rightarrow 7 \cdot 8$

$3 \cdot 9$

$5 \cdot 1 \rightarrow 10 \cdot 2$

$6 \cdot 7$

$3 \cdot 2 \rightarrow 12 \cdot 0$

In all three age groups the VMA levels were raised in the children with spina bifida, but pars ticularly in the older age group where the average values were more than three times greater than normal. Altogether $74 \%$ of the children had excretion values in excess of the upper level of normal fo their age. The HVA levels were even higher in the्ठ affected children, the average being about thre times normal. The pHPAA levels were higher in al groups, again by a factor of about 3 , and altogethes $87 \%$ had values above the upper limit of normal Within the groups there was rough correlation between the HVA and VMA levels while the pHPAA levels appeared to be independent of the other two. There were only two children out of the total of 55 who did not have an excretion level abover. the upper limit of normal of one or other of the three compounds.

TABLE I

SUMMARY OF CLINICAL AND BIOCHEMICAL FINDINGS Age (yr)

\begin{tabular}{llllll}
\hline $0-2$ & & $2-5$ & & & Over 5 \\
\cline { 1 - 1 } $\begin{array}{l}\text { Control } \\
(20)\end{array}$ & $\begin{array}{l}\text { Meningomyelocoele } \\
(19)\end{array}$ & $\begin{array}{l}\text { Control } \\
(20)\end{array}$ & $\begin{array}{l}\text { Meningomyelocoele } \\
(16)\end{array}$ & $\begin{array}{l}\text { Control } \\
(20)\end{array}$ & $\begin{array}{l}\text { Meningomyelocoele } \\
(20)\end{array}$
\end{tabular}

VMA ( $\mu \mathrm{g} / \mathrm{mg}$ creatinine)

Range

Mean

HVA ( $\mu \mathrm{g} / \mathrm{mg}$ creatinine)

Range

Mean

pHPAA $(\mu \mathrm{g} / \mathrm{mg}$ creatinine $)$

Range $^{1}$

\begin{tabular}{ll}
$2 \cdot 0-14 \cdot 0$ & $7 \cdot 0-28 \cdot 3$ \\
8 & 14 \\
& \\
$2 \cdot 9-11 \cdot 3$ & \multicolumn{1}{l}{$6 \cdot 4-35 \cdot 0$} \\
$6 \cdot 5$ & $16 \cdot 5$ \\
& \\
$4 \cdot 3-17 \cdot 3$ & $12 \cdot 0-100$ \\
$10 \cdot 7$ & $33 \cdot 9$
\end{tabular}

(20)

$2 \cdot 0-8 \cdot 0 \quad 7 \cdot 0-27 \cdot 3$

$\begin{array}{ll}5 & 12 \cdot 8\end{array}$

1.8-7.0 7.0-27.3

$4.9 \quad 14.6$

$3 \cdot 8-15 \cdot 2 \quad 14 \cdot 0-100$

$8 \cdot 6 \quad 39 \cdot 1$

(20)

$\begin{array}{ll}2 \cdot 0-6 \cdot 0 & 7 \cdot 1-24 \cdot 0 \\ 4 & 12 \cdot 4 \\ & \\ 2 \cdot 8-6 \cdot 7 & 6 \cdot 7-31 \cdot 0 \\ 4 \cdot 4 & 13 \cdot 3 \\ & \\ 3 \cdot 8-15 \cdot 2 & 9 \cdot 5-68 \\ 9 \cdot 8 & 33 \cdot 8\end{array}$

${ }^{1}$ The pHPAA levels in normals was determined in $\mathbf{1 0}$ patients in all three groups. 


\section{DISCUSSION}

The finding of high levels of pHPAA in the urine of these children confirms the previous findings of McKibbin et al (1968), where the method of estimation used was that of Tompsett (1958). In addition it is evident that the VMA and HVA levels also are raised by an average factory of about 3 . These values have necessarily been expressed as a ratio of creatinine excretion, and therefore suffer from the disadvantage that should the level of creatinine excretion be lower than normal the values obtained will be artificially raised. There is perhaps some reason to suspect that creatinine levels may in fact be low in these children, many of whom have extensive paralysis and therefore a low muscle mass, but this fact alone is hardly sufficient to explain levels which are on average three times greater than normal. Additional reasons for so thinking are afforded by the fact that the pHPAA levels in a given case appeared to be quite unrelated to the levels of the other two compounds and there was no very obvious relationship between any of the levels and the degree of paralysis.

It appears likely, therefore, that in meningomyelocoele there is an abnormality in the metabolic pathway of tyrosine. The metabolic defect may be an inborn error which is part of the basic syndrome, and if this is so it is possible that it is the cause rather than the result of the malformation. There is some relationship with phenylketonuria which is the consequence of a metabolic error in the conversion of phenylalanine to tyrosine (Fig. 1), and is associated with damage to the central nervous system. In this connexion it is noteworthy that pHPAA is one of the metabolites which has been identified in excessive quantities in the latter condition (Boscott and Bickel, 1953).

An alternative explanation is that the abnormality is itself the result of the malformation or one of its secondary features, such as hydrocephalus, paraplegia, or urinary dysfunction. There is particular reason to suspect hydrocephalus since raised levels of HVA have been found in the cerebrospinal fluid of hydrocephalics by Andersson and Roos (1965), although it is not clear from the published data how many of their cases were in fact associated with spina bifida. This possibility requires more detailed study with the object of correlating the metabolic abnor- mality with particular clinical features. All that can be said from the present study, based on a crude clinical appraisal of the children in the group, is that there was no obvious association with any particular clinical feature. The fact that a metabolic abnormality was found in almost every case using only a single random specimen of urine suggests that it is more likely to be associated with the basic malformation rather than with one of its inconstant secondary features.

The relationship of the previously reported vitamin C deficiency (McKibbin and Porter, 1967) is not clear. Evidently the finding of raised pHPAA levels cannot of themselves be regarded as certain evidence of simple vitamin $\mathrm{C}$ deficiency in view of the other derangements in tyrosine metabolism which have been demonstrated. One possibility is that in view of the high rate of formation of HVA and VMA the vitamin is excessively utilized.

Obviously it is essential to resolve the question as to whether these metabolic abnormalities are primary or secondary, and this can most easily be done by repeating the investigations in children with hydrocephalus, paralysis, or urinary dysfunction which are not associated with meningomyelocoele. These investigations have been started, and it is hoped that other workers having access to more of such cases than ourselves might be tempted into a similar study.

Our grateful thanks are due to Dr A. Jordan for advice and encouragement, and to Miss E. Holberry for invaluable technical assistance.

\section{REFERENCES}

Andersson, H., and Roos, B. E. (1965). Acta neurol. scand., Suppl., 13, 149.

Bonsnes, R. W., and Taussky, H. H. (1945). J. biol. Chem., 158, 581. Boscott, R. J., and Bickel, H. (1953). Scand. J. clin. Lab. Invest., 5, 380.

Boscott, R. J., and Cooke, W. T. (1954). Quart. J. Med., 23, 307.

Gitlow, S., Mendlowitz, M., Wilk, E. K., Wolf, R., and Glick, J. (1965). J. clin. Invest., 44, 1049.

Gjessing, L. R. (1963). Scand. J. clin. Lab. Invest., 15, 463.

Hermann, G. A. (1964). Amer. J. clin. Path., 41, 373.

Levin, E. Y., Levenberg, B., and Kaufman, S. (1960). J. biol. Chem., 235, 2080.

O'Gorman, L. P. (1968). Clin. chim. Acta, 19, 485.

McKibbin, B., and Porter, R. W. (1967). Develop. Med. Child Neurol., 9, 338.

—_, Toseland, P. A., and Duckworth, T. (1968). Ibid., suppl. 15, 55.

Studnitz, W. von (1960). Scand. J. clin. Lab. Invest., suppl. 48.

Tompsett, S. L. (1958). Clin. chim. Acta, 3, 149. 